\title{
Globalização e políticas públicas no Brasil: a privatização das comunicações entre 1995 e $1998^{1}$
}

\section{VENÍCIO A. DE LIMA*}

A recente universalização do princípio neoliberal da abertura plena dos mercados, que impõe aos Estados a privatização de suas empresas, implica alguns pressupostos que, todavia, não são universais. Apesar das profundas transformações porque passa o mundo contemporâneo, inclusive no campo ideológico, pressupostos que se referem ao papel do Estado, ao papel do Governo, a quais são os principais atores políticos, a como os interesses público $e$ privado são definidos etc. têm raízes culturais sólidas e, em algumas sociedades, não se alteram com facilidade, exatamente pelo muito que representam em termos de história e tradição.

A universalização neoliberal, muitas vezes identificada com o processo de globalização, traz implicações diretas para a formulação de políticas públicas e, portanto, para a vida do cidadão comum. Quais serão as conseqüências finais das privatizações é uma questão que não se pode ainda compreender e avaliar nas suas diversas dimensões, embora muitos considerem acriticamente o processo como necessariamente positivo. Para o cidadão comum, todavia, sobretudo quando as novas políticas implicam mudanças de valores e de percepções que, até pouco tempo atrás, eram inequivocamente aceitas como centrais na cultura política brasileira, a avaliação ainda é uma questão aberta.

Este trabalho é um estudo de caso do descompasso existente entre o princípio neoliberal da abertura plena dos mercados - que orienta o Governo de Fernando Henrique Cardoso (FHC) - e a cultura política dominante no Brasil. Tomarei como exemplo a nova política de privatização das comunicações.

Os dados disponíveis indicam que persiste, na maioria da população brasileira, uma imagem positiva de "patrimônio público" historicamente associada a empresas do Estado que se transformaram em símbolos de soberania, independência e identidade nacional. Algumas dessas empresas já foram 
privatizadas, como é o caso da Companhia Siderúrgica Nacional, da Vale do Rio Doce e da Telebras. Outras ainda não, como a Petrobras e o Banco do Brasil.

Essa histórica imagem positiva seria uma das razões que explica o fato de que $46 \%$ da opinião pública brasileira continue acreditando que "nada vai mudar" ou vai "piorar” com o processo de privatização (IBOPE, 3/1998) ou que o Governo "está apenas se desfazendo do patrimônio do Estado e favorecendo os grandes grupos empresariais” (Vox Populi, 17/8/1998).

Talvez essa também seja uma das razões para que a privatização do Sistema Telebras, a maior já realizada na história da América Latina, ter tido uma reprovação de 51\% da opinião pública paulistana (DataFolha, 25/7/1998). Registre-se que esse elevado índice de reprovação foi verificado apesar dos opositores terem sido identificados pelo Presidente da República como "retrógrados, que pensam que o Brasil ainda está na década de 50" (Galhardo, R; 27/7/1998) e de "ignorantes”, "despreparados”, “chantagistas”, “destrutivos”, "negativistas”, “desqualificados” e "impatrióticos” pelo Ministro das Comunicações (Pinheiro, A.J.; 30/7/1998 e Fernandes, B.; 19/8/1998).

Na verdade, desde que iniciou a implementação do Programa Nacional de Desestatização (PND) em 1991, o Brasil se transformou em líder mundial das privatizações tanto no que se refere à velocidade e importância econômica das empresas privatizadas (Barbosa, R.; 29/7/1997) quanto ao volume de recursos envolvidos, suplantando seus vizinhos da América Latina, países como a Itália, a Alemanha e a Espanha, e até mesmo a Inglaterra, onde nasceu e prosperou a idéia (Rodrigues, F.; 7/4/1998). Apesar disso, essa talvez seja uma das poucas áreas onde o Governo de FHC, iniciado em 1995, não encontre aprovação da maioria da opinião pública brasileira.

Quais as razões para esse descompasso entre a ação do Governo e a opinião pública? Por que a maioria dos brasileiros não está convencida de que a privatização de empresas do Estado é feita em benefício do Brasil, como diz a insistente propaganda oficial?

\section{Estado vs. Governo}

A resposta a essas perguntas exige uma pequena digressão e tem a ver com aspectos singulares que decorrem das percepções de Estado e de Governo predominantes na cultura política brasileira.

De fato, para o cidadão brasileiro comum, creio ser correto afirmar que as noções de Estado e de Governo se distinguem com uma nitidez surpreendente: o Estado é percebido como uma instituição permanente, gerenciada por uma burocracia estável que se materializa através de centenas de autarquias ou repartições públicas espalhadas pelo território nacional. Esse Estado é, portanto, uma instituição não só capaz mas, sobretudo, com o dever de proteger o interesse 
público, seja ele territorial, estratégico, econômico, cultural ou qualquer outro. Isso não significa, todavia, que esse Estado seja percebido como instituição neutra, democraticamente repartindo os recursos que administra, mas sim como sendo a instancia que naturalmente teria as condições para fazê-lo. O papel do Estado se equaciona, portanto, com o interesse público.

Já o Governo é percebido como transitório, composto por políticos que circunstancialmente desfrutam do poder por controlarem a máquina administrativa do Estado. Aqueles que compõem o Governo se tornam poderosos sobretudo porque controlam os recursos que o Estado arrecada através de impostos e que podem então ser redistribuídos de acordo com os seus interesses privados transitórios. Enquadra-se nessa percepção de Governo a maneira como a maioria dos eleitores ainda define o papel dos Deputados Federais e aquilo que eles deveriam fazer, ou seja, redistribuir os recursos públicos para a sua constituency (cf. Vox Populi, 6/8/ 1998). O papel do Governo, portanto, se equaciona com o interesse privado.

Em outros países, como nos Estados Unidos, por exemplo, a percepção dominante das noções de Estado e Governo não os separa nitidamente como instituições representativas de interesses diferentes. Na verdade, os próprios analistas políticos americanos dificilmente se utilizam do conceito de Estado que é, muitas vezes, substituído por Governo. Nesta direção, há de se notar que várias unidades acadêmicas que estudam a Ciência Política nas universidades americanas (Harvard, por exemplo) são departamentos de Government, vale dizer, estão subsumidas na idéia de Government as várias noções que constituem o objeto de estudo da Ciência Política, dentre elas, naturalmente, a noção de Estado. Além disso, o Government é freqüentemente associado, na linguagem dos mídia, à “administração" corrente. É comum, por exemplo, encontrar-se referências a the Clinton Administration, referindo-se ao Governo do Presidente Clinton. A referência a Estado (State) é reservada quase que exclusivamente às unidades da federação como, por exemplo, ao State of Illinois ou ao State of Montana. Esses fatos dissolvem ainda mais as noções de Estado e Governo. Dessa forma, percebese o interesse público e o interesse privado, em particular das empresas privadas, como convergindo no Governo.

Arrisco-me, portanto, a sugerir que a maioria dos brasileiros não está convencida de que a privatização de empresas do Estado é feita em benefício do Brasil porque, ao contrário de países como os Estados Unidos, existe uma diferenciação clara entre Estado e Governo e de seus papéis. Na nossa cultura política, por razões históricas e culturais, o Estado não é percebido como representante direto do interesse privado, em particular das empresas privadas. Estas, por sua vez, são percebidas como tendo interesses não necessariamente coincidentes com aqueles do conjunto da população, vale dizer, com interesses públicos. Além disso, no Brasil, a percepção dominante na cultura política de fato corresponde à construção simbólica do papel historicamente desempenhado pelo Estado brasileiro ou, em outras palavras, é uma percepção correta. 
Nos Estados Unidos, por outro lado, é também correta a percepção dominante, oposta à brasileira, que faz convergir no Governo a representação dos interesses público e privado. Lá é rotina, por exemplo, na política externa, a identificação direta dos interesses do Estado (públicos) com os interesses das grandes empresas (privados), tanto assim que a diplomacia americana é, às vezes, chamada de "diplomacia comercial” das grandes empresas, sendo o próprio Presidente da República identificado como seu principal articulador (cf. Huntington, S.; 1997).

\section{Nova política}

Todas essas considerações se fazem necessárias para retomar o tema central deste artigo. Dentro do quadro de referência acima esboçado, pretendo argumentar que o processo de privatização de empresas do Estado, promovido a partir dos anos 90 e acelerado no Governo de FHC, implica a execução de uma nova política com pelo menos duas características principais:

(1) políticas nacionais com forte componente internacional ou global players (Governos, empresas e/ou organismos internacionais), participando ativamente da definição de políticas nacionais; e

(2) políticas nacionais e/ou externas que articulam como coincidentes os interesses do Estado (públicos) e de grandes grupos empresariais nacionais e/ou transnacionais (privados) ${ }^{2}$.

O caso paradigmático dessa nova política é a política de comunicações que vem sendo executada a partir de 1995. Refiro-me a uma única política de comunicações e não às diferentes políticas públicas que até recentemente eram articuladas isoladamente para as áreas de telecomunicações, mass media (radiodifusão) e informática. Como é sabido, provocada pela revolução digital, a chamada convergência tecnológica está dissolvendo as fronteiras entre o telefone, a televisão e o computador (a Internet). Decorre daí a inevitável fusão das antigas políticas setoriais em uma única política de comunicações.

Embora, no Brasil, o reconhecimento público dessa nova realidade ainda seja tímido, o que já se discute, por exemplo, na Comunidade Européia, é a exigência, a curto prazo, de uma regulação única do setor. Em trabalho recente, Cowie e Mardsen (1998) afirmam: "the regulatory implications of convergence are both the substantive issues of access to technical services and the question of institutional design of the regulatory framework. Historically, the commercial separation of telecommunications and television has been mirrored with separate regulatory authorities, but with convergence, the commercial distinctions are being eroded and the rationale for multiple regulation is being questioned. In particular there is a view that the convergence of markets 'requires' a merger of the sectoral regulators to form a single communications regulator".

São os diferentes aspectos desse caso paradigmático que discutirei a seguir. 


\section{A política de comunicações}

Tomarei como exemplo básico dentro da formulação da política de comunicações a Lei Geral de Telecomunicações-LGT (Lei 9.472 de 16 de julho de 1997). Como se sabe, ao lado da Lei da TV a Cabo (Lei 8.977/1995) e da Lei Mínima (Lei 9.295/1996), a LGT define a estrutura legal básica das reformas iniciadas com a quebra do monopólio estatal das telecomunicações através da Emenda Constitucional n. 08, aprovada em 15 de agosto de 1995, menos de 8 meses após a posse do Presidente FHC.

Essa nova política favorece a concentração da propriedade porque não impede a propriedade cruzada dos grupos empresariais de telecomunicações, comunicação de massa e informática ${ }^{3}$; e estimula a participação crescente dos global players, diretamente ou associados aos grandes grupos nacionais, na medida em que elimina todas as barreiras para a entrada do capital estrangeiro (Lima, 1998b).

Neste artigo, vou concentrar a análise da LGT na descrição de procedimentos e de conseqüências relacionadas à contratação de consultores externos que definiram o desenho básico do Projeto de Lei (PL 2.648/96) submetido ao Congresso Nacional em 12 de dezembro de 1996; e, em seguida, nas negociações sobre o Acordo Geral de Telecomunicações na Organização Mundial do Comércio, que ocorreram paralelamente à tramitação do Projeto no Congresso Nacional. (cf. Cronologia Geral, anexa). Enfatizarei a questão central da abertura do mercado brasileiro ao capital estrangeiro (privado e/ou estatal), vale dizer, aos global players, por ser este um aspecto síntese das duas características principais da nova política do Governo de $\mathrm{FHC}^{4}$ e considerarei, também, algumas das conseqüências concretas em termos de formulação de política após a aprovação da LGT e do Acordo na OMC.

Antes, porém, de discutir especificamente as questões que nos interessam, vale mencionar duas características específicas do setor de comunicações.

Primeiro, nunca será demais insistir que nos estamos referindo a um setor que envolve enormes somas de recursos financeiros. O setor de comunicações já ultrapassou áreas, como a exploração de petróleo e de minérios, que, até recentemente, eram consideradas como "bons negócios".

No Brasil, anúncio do Ministério das Comunicações, fartamente veiculado nos mídia no final de 1996, prometia o segundo maior plano de investimentos no setor do planeta, logo depois da China, no valor de 75 bilhões de reais (VEJA, Ed. 1476). Poucos meses depois, em março de 1997, esses valores foram revisados e o total de investimentos previstos até 2.003 aumentou para 83,5 bilhões de reais (Lobato, E., 21/03/1997). Além disso, estimativa do Banco Lloyds de Londres antecipa em 95 bilhões de dólares o valor total da privatização das telecomunicações brasileiras até o mesmo ano de 2.003 (VEJA, Ed. 1501) ${ }^{5}$. 
Segundo, estudiosos têm advertido que as comunicações estão sujeitas ao estabelecimento de padrões de base técnica - necessários para assegurar a integridade da arquitetura de redes paralelamente ao avanço tecnológico - que, por sua vez, definem regiões tecnológicas, isto é, conjuntos de alianças internacionais, formais e/ou informais, construídas para promover, consolidar e coordenar as atividades relacionadas às comunicações dentro de órbitas relativamente delimitadas de influência econômica e política.

Estudos recentes indicam que a definição desses padrões de base técnica e, portanto, de regiões tecnológicas tem ocorrido, sobretudo, no espaço de decisão de três organismos vinculados aos Estados-nacionais onde se concentram os mesmos global players que, progressivamente, vão assumindo o controle do setor, isto é, a Comissão “T1" dos Estados Unidos, a Telecommuncations Technology Committee - TTC do Japão e a European Telecommunications Standards Institute - ETSI da União Européia (Hawkins, R., 1995; pp.53-58, passim).

Registradas a magnitude econômico-financeira do setor de comunicações e as restrições de ordem técnico-política existentes no seu controle, retorno agora a análise da LGT.

\section{Os consultores internacionais e a formulação do Projeto da LGT}

Ainda em 1995, tão logo o Congresso Nacional aprovou a Emenda Constitucional que quebrou o monopólio estatal das telecomunicações, o Ministério das Comunicações -MiniCom celebrou um Acordo Administrativo com a UIT União Internacional de Telecomunicações, "visando a obtenção de apoio técnico e metodológico com vistas à modernização do setor de telecomunicações”. No início de 1996, constatou-se que o melhor instrumento para o objetivo desejado pelo MiniCom era um Termo de Cooperação e não um Acordo Administrativo. Dessa forma, em junho de 1996, foi assinado o referido Termo entre o Governo brasileiro e a UIT (UIT No. 9-BRA/95/05), com um orçamento inicial de 5,1 milhões de dólares, posteriormente ampliado para cerca de 16,6 milhões. Em ambos os casos, todavia, na interpretação do MiniCom, não havia exigência de licitação por se tratar da contratação de serviços técnicos com profissionais ou empresas especializadas ${ }^{6}$.

Entre os componentes do Projeto objeto do Termo de Cooperação está prevista uma Consultoria Internacional para cobrir os seguintes aspectos: (a) desenvolvimento do modelo econômico que dará sustentação à proposta de reforma estrutural do setor; (b) análise do impacto potencial das disposições da nova lei de telecomunicações sobre a oferta e a demanda, utilizando o modelo econômico citado; (c) análise das alternativas possíveis para a adequação do sistema Telebras ao novo contexto econômico-institucional; e (d) privatização de empresas estatais na área de telecomunicações (cf. Documento de Projeto, 4.1. Consultoria Internacional, Anexo ao UIT No.9-BRA/95/05). 
Para desenvolver este trabalho e dentro das normas licitatórias do Termo inicial de Cooperação, a UIT contratou como principal consultor internacional a McKinsey \& Company, Inc. Quase um ano mais tarde, em abril de 1997, a McKinsey seria novamente contratada, agora para substituir como segunda colocada a Coopers \& Lybrand, que por "razões operacionais" (sic) teve seu contrato encerrado. O primeiro contrato foi no valor de US\$1,17 milhão e o segundo no valor de US\$ 3,5 milhões, em um total de 4,67 milhões de dólares ${ }^{7}$.

Para a compreensão desses procedimentos e de suas implicações no desenho da LGT, é necessário que se lembre, embora por demais sabido, o que são a UIT e a McKinsey. Vejamos.

Estudiosos da área têm constatado a progressiva transformação da UIT, nos últimos anos, no contexto da redefinição da comunicação e da informação de serviço público para propriedade privada. Vale dizer, as comunicações passam a ser consideradas um serviço que pode ser comercializado como qualquer outro. Isto apesar de se saber que "if there is a conceptual model which is precisely opposite the precepts of trade, surely it is telecommunications" (Allen, D.; 1998). Jill Hills (1997) afirma que "a década de 80 assinalou o surgimento de uma forma de privatização de instituições internacionais como a UIT, onde o conceito prévio de soberania nacional começou a ser minado por pressões em admitir interesses privados nas negociações.”

Essas transformações correspondem a uma ação liderada pelos EUA através de um processo que começa antes mesmo da Rodada Uruguay do GATT e culmina com a criação da OMC e a assinatura do Acordo Geral sobre Telecomunicações em 1997. Esse processo, chamado por Comor (1997) de "GATTization of the ITU” foi assim por ele descrito: "ITU procedures - traditionally dominated by nation-state officials and interested hardware manufacturers subsequentely were opened up to corporate officials as well as industrial and scientific organizations in order to incorporate the interests of telecommunication distributors and users directly into the regulatory process" (p.199). O resultado desse processo é que "o poder dos interesses comerciais, enormemente auxiliados pelos Estados Unidos, deslocaram os termos e o terreno através do qual as decisões sobre as telecomunicações deveriam ser tomadas” (Mahoney, 1997) ${ }^{8}$.

Essa nova UIT apresenta-se na Internet como "an international organization within which governments and the private sector coordinate global telecommunication networks and services” (cf. <www.itu.ch>). A UIT, portanto, é um organismo das Nações Unidas onde, além dos Estados, estão presentes 514 membros distribuídos nas seguintes categorias:, 205 Recognized Operating Agencies - ROA; 226 Scientific or Industrial Organizations-SIO; 18 Other Entities dealing with telecommunication matters; 47 Regional and Other International Organizations; 11 Regional Telecommunication Organizations e 7 Intergovernmental Organizations operating satellite systems. 
Dentre esses 514 membros, encontram-se inúmeros global players que estão agora se tornando conhecidos dos brasileiros como Telefónica de Espanha, Bell South, MCI (WorldCom), Motorola, News Co. (Sky), NTT, Telia , TCI e outros.

Já a McKinsey é uma das maiores empresas de consultoria do mundo, com 75 escritórios em 38 países, inclusive no Brasil, e assessora governos e empresas "tais como aquelas na lista das 500 maiores dos EUA da revista Fortune e suas equivalentes nos respectivos países”. Kenichi Ohmae, sócio-senior por mais de 20 anos da McKinsey no Japão, ficou mundialmente famoso ao publicar o livro O Fim do Estado Nação, em 1995 - dedicado, aliás, aos seus ex-colegas da McKinsey - onde argumenta que, além de ineficientes, os Estados nacionais são apenas "dinossauros esperando a morte". No Brasil, os sócios da McKinsey, Albrecht Curt Reuter e Heinz-Peter Elstrodt, defenderam em entrevista recente (17/8/1998, Época) a assinatura do Acordo Multilateral sobre o Investimento (AMI) que vem sendo preparado desde 1995 pela OCDE - Organização para a Cooperação e Desenvolvimento Econômico, que reúne os 29 países mais ricos do mundo. Esse Acordo, como se sabe, tem provocado polêmica porque sua celebração é considerada por muitos como o fim definitivo da autonomia dos Estados nacionais (Moberg, D.; 3/1998).

A contratação pelo Governo brasileiro da McKinsey, através da UIT, revela o componente internacional da LGT, uma das caracteríticas da nova política. A UIT, um organismo das Nações Unidas, transformou-se, como vimos, em um espaço de atuação e exercício de poder dos global players do setor. A McKinsey - ela própria uma grande consultura internacional - está em sintonia com os interesses desses global players, muitos deles clientes seus.

Por outro lado, a articulação como coincidentes dos interesses públicos e privados - a outra característica da nova política - se revela a partir da análise do próprio PL da LGT: o projeto de Lei foi desenhado, dentre outros aspectos, para atrair os investidores estrangeiros. Todas as outras considerações com relação à formulação da política do setor ficam submetidas a essa prioridade número um. Neste sentido, o PL e o desenho da privatização da Telebras proposto pela McKinsey (cf. MiniCom/Mckinsey, 11/1996) adequaram-se perfeitamente aos objetivos do Governo preparando o caminho legal para a participação - sem restrições - do capital internacional no processo, como de fato veio a ocorrer.

A Tabela 1 abaixo ilustra a participação de global players - membros da UIT - no processo de privatização do DTH e da telefonia celular de banda B (Lei Mínima) e das telefonias fixa e celular de banda A (LGT). Além disso, indica a relação da McKinsey com alguns dos países de origem desses global players. 


\section{TABELA 1}

\section{PARTICIPAÇÃODE MEMBROSDAUIT NAPRIVATIZAÇÃO DAS COMUNICAÇÕES NO BRASIL}

\section{a. DTH (satélite)}

\begin{tabular}{|l|l|l|l|}
\hline \multicolumn{1}{|c|}{ Empresas } & \multicolumn{1}{|c|}{ Origem } & \multicolumn{1}{c|}{ Área geográfica } & \multicolumn{1}{c|}{ Parceiros Brasileiros } \\
\hline Hughes & Estados Unidos \# & Brasil/A. Latina & Abril/DirectTV \\
News Corporation & Austrália \# \$ & (satélite) & Globo/Sky \\
TCI & Estados Unidos & & Globo/Sky \\
Televisa & México & & Globo/Sky \\
\hline
\end{tabular}

\section{b. Telefonia Celular de banda B}

\begin{tabular}{|l|l|l|l|}
\hline \multicolumn{1}{|c|}{ Empresas } & \multicolumn{1}{|c|}{ Origem } & Área geográfica adquirida & \multicolumn{1}{c|}{ Parceiros Brasileiros } \\
\hline BellSouth & Estados & 1 - Grande São Paulo & Safra-OESP-RBS \\
DDI Corporation & Unidos & 5 - Paraná e Santa Catarina & Splice/BCP \\
& Japão \# \$ & 3 - R. J. e Espírito Santo & Suzano- \\
Korea Mobile & Coréia do Sul \# & 5 - Paraná e Santa Catarina & Inepar/Globaltelecom \\
Telecom & Estados & 4 - Minas Gerais & Algar-Queiroz Galvão/Algar \\
Motorola & Unidos & 9 - Bania e Sergipe & Suzano- \\
Telecom Itália & Itália \# & 2 - São Paulo (interior) & Inepar/Globaltelecom \\
(Stet) & Suécia \# \$ & & Vicunha- \\
Telia & & & Globo/Bradesco/Maxitel \\
& & & Vicunha-Globo- \\
& & & Bradesco/Maxitel \\
& & & \\
\end{tabular}

\section{c. Telefonia Fixa e Celular de banda A (Telebras)}

\begin{tabular}{|c|c|c|c|}
\hline Empresa & Origem & $\begin{array}{c}\text { Subsidiária da Telebras } \\
\text { adquirida }\end{array}$ & Parceiros Brasileiros \\
\hline $\begin{array}{l}\text { MCI } \\
\text { NTT Mobile Comunic. } \\
\text { Portugal Telecom } \\
\text { Telecom Itália }\end{array}$ & $\begin{array}{l}\text { Estados } \\
\text { Unidos } \\
\text { Japão } \\
\text { Portugal\# } \\
\text { Itália \# } \\
\text { Espanha\# \$ }\end{array}$ & $\begin{array}{l}\text { Embratel } \\
\text { Tele Sudeste Celular } \\
\text { Telesp/ } \\
\text { Telesp Celular } \\
\text { Tele Nordeste Celular } \\
\text { Tele Celular Sul } \\
\text { Tele Centro Sul } \\
\\
\text { Telesp } \\
\text { Tele Sudeste Celular } \\
\text { Tele Leste Celular }\end{array}$ & $\begin{array}{l}\text { Não houve/MCI } \\
\text { Não houve/Tele. } \\
\text { Espanha } \\
\text { RBS/Telebrasil Sul } \\
\text { Nãohouve/Portugal } \\
\text { Telecom } \\
\text { Globo-Bradesco/UGB } \\
\text { Bitel Globo } \\
\text { Bradesco/UGB-Bitel } \\
\text { Fundos Pensão } \\
\text { Opportunity/ } \\
\text { Solpart Participações } \\
\text { RBS/Telebrasil Sul } \\
\text { Não houve/Tele. } \\
\text { Espanha } \\
\text { Não houve/Iberdrola }\end{array}$ \\
\hline
\end{tabular}

\# A Mckinsey \& Company possui escritórios nestes países.

$\$$ A Mckinsey \& Company já prestou consultoria para os governos destes países. 
2. As negociações do Acordo de Telecomunicações na OMC, a tramitação do PL no Congresso Nacional e a LGT

A Organização Mundial do Comércio - OMC, que iniciou suas atividades formalmente em janeiro de 1995 e foi criada para substituir o Acordo Geral de Comércio e Tarifas - GATT, altera de forma substantiva a realidade do comércio mundial, que agora inclui, também, as comunicações. Um especialista comenta que "o GATT, de simples acordo geral, passou à OMC, com o mesmo status jurídico e poder político das demais organizações multilaterais como Banco Mundial e FMI. Dentro das suas novas funções foi renegociado todo um sistema de solução de controvérsias que agora obriga os membros da organização a aceitarem as conclusões dos grupos de peritos e do órgão de apelação criado para analisar os conflitos do comércio internacional” (Thorstensen, 1998).

Além disso, no novo contexto das relações internacionais, é sabido que, em organismos multilaterais como a OMC, "as tradicionais hierarquias das relações intergovernos estão sendo substituídas por novas formas de lealdade e parcerias, baseadas em interesses econômicos mútuos e respectivas vantangens locacionais, facilitadas pela atuação de empresas transnacionais de vários tipos” (Hawkins, R.;1995, p.49).

É dentro desse novo contexto - comunicações transformadas em serviço e crescente importância dos global players (empresas transnacionais) - que ocorre a tramitação do Projeto da LGT no Congresso Nacional. Vejamos.

Uma das áreas sobre as quais não se obteve acordo na chamada Rodada Uruguai do GATT (que se iniciou em 1986 e se estendeu até 1993), dentro do comércio de serviços, foram as telecomunicações, incluindo telefonia convencional, transmissão de dados, telex, telégrafos, fax, circuitos privados de transmissão, sistemas de satélites móveis e fixos, telefonia celular e paging ${ }^{9}$.

Considerando que estudo realizado pela própria OMC identificou o Brasil como "o país em desenvolvimento que mais oferece oportunidade de lucro nesse setor” (Berlinck, D., 16/2/1997), é de se supor que deveria existir grande interesse dos global players das comunicações no mercado brasileiro.

Havendo assinado o Acordo Geral sobre Comércio de Serviços na reunião do GATT/OMC realizada em Marrakesh em abril de 1994, o Governo brasileiro seguiu sofrendo fortes pressões internacionais para fazer uma "boa oferta" ao acordo específico das telecomunicações. Essas pressões partiam, sobretudo, dos Estados Unidos e do Fórum Econômico Mundial, realizado em Davos, em janeiro/ fevereiro de 1997, portanto, às vésperas do prazo final para a assinatura do Acordo sobre Telecomunicações na OMC, foi uma das ocasiões em que essa pressão direta ficou mais evidente.

Reunindo cerca de 2.000 empresários, políticos, economistas e analistas com a "finalidade de melhorar o mundo e oferecer soluções para os problemas 
globais”, fazem parte do Fórum empresas que vão desde a Nestlé à Microsoft, da Coca-Cola à General Eletric e o brasileiro Unibanco. Um dos temas do encontro de 1997 foi "a revolução da tecnologia da informação e seus impactos sobre a sociedade pós-industrial”. Durante o encontro, emergiu com clareza a pressão americana através do subsecretário de Comércio Internacional, exigindo a abertura total do mercado de telecomunicações à participação estrangeira. As manchetes da imprensa brasileira no período de realização do Forum revelam o clima predominante: "Teles é área de divergência”. A posição americana era chamada de "ultimato" ou "Governo americano exige abertura de mercado sob pena de não haver mais qualquer acordo comercial" ou ainda "EUA cobram do Brasil abertura rápida” (cf. cobertura da FSP; dias 22/01; 2, 3 e 4/02/1997).

A pressão dos EUA não era novidade, de vez que era sabido, através de diferentes altos funcionários do governo americano, que "To make this agreement work during the transition ahead, the United States has to be united in purpose and willing to use all available means - including both carrots and sticks - to build the WTO framework". Além disso, "the pivotal reference paper was modeled in large part upon the principles embodied in the US '96 Telecommunications Act "' (cf. Allen, D.; 1998; p. 9)

O Governo brasileiro foi receptivo a essas pressões. De fato, a própria Exposição de Motivos n. 231/MC que acompanhou o PL da LGT ao Congresso Nacional em dezembro de 1996 já se referia antecipadamente à possibilidade de incluir as disposições da nova lei à oferta brasileira nas negociações da OMC (cf. p. 56).

Quando um Acordo Global sobre Telecomunicações foi finalmente celebrado no âmbito da OMC em fevereiro de 1997, a oferta do Brasil se conteve dentro dos limites já estabelecidos pela Lei Mínima, isto é, 49\% de participação do capital estrangeiro até julho de 1999 para as áreas de "serviços móvel celular, por satélite, limitados e de valor adicionado” (Art. 11). Isso, todavia, não impediu que outro compromisso fosse assumido pelo Governo brasileiro, nos seguintes termos: “dentro de um ano, após a sanção pelo Presidente da República do atual projeto de Lei Geral de Telecomunicações (isto é, a partir de 16/7/1998), o Brasil introduzirá em sua Lista compromissos relacionados à exploração de serviços públicos de telecomunicações, incorporando as disposições relevantes da nova Lei referentes ao Acesso ao Mercado" (cf. item 2.C.3 da Lista de Compromissos Específicos do Quarto Protocolo do Acordo Geral sobre o Comércio de Serviços - AGCS).

A confirmação da posição brasileira ocorreu em 24 de junho de 1997, quando o documento que consolida a oferta dos 70 países participantes foi assinado na OMC, em Genebra. A partir dessa assinatura, a oferta brasileira torna-se engajada diante do direito internacional e tem força obrigatória nos termos do AGCS desde que seja ratificada pelo Congresso Nacional (Constituição de 1998, Artigo 84, item VIII) o que, todavia, mais de um ano e quatro meses depois, ainda não aconteceu. ${ }^{10}$ 
A abertura total do mercado - exigência dos Estados Unidos tanto em Davos-97 quanto durante a Rodada Uruguai e, posteriormente, nas negociações específicas já no âmbito da OMC - acabou se transformando também em um dos pontos polêmicos na tramitação do projeto da LGT que ocorria, como mencionado, paralelamente às negociações de Genebra.

Logo após a celebração do Acordo Global sobre Telecomunicações, o presidente da Comissão de Ciência e Tecnologia, Comunicação e Informática da Câmara dos Deputados, publicou artigo na imprensa defendendo a abertura total do mercado brasileiro (Lopes, N., 21/02/1997). Emendas foram apresentadas por deputados que apoiam politicamente o Governo de FHC, propondo a abertura total do mercado ao capital estrangeiro e o texto finalmente aprovado e transformado em Lei usou o artifício de transferir ao Presidente da República o poder de estabelecer os limites para essa participação. O texto da Lei diz que "o Poder Executivo, levando em conta os interesses do País no contexto de suas relações com os demais países, poderá estabelecer limites à participação estrangeira no capital de prestadora de serviços de telecomunicações” (LGT, Parágrafo Único do Artigo 18).

Apenas 10 meses depois - antes do prazo estabelecido no AGCS da OMC para que o Brasil incorporasse as disposições da LGT à sua Lista de Compromissos (16/7/1998) -, o Presidente Fernando Henrique Cardoso, com base no dispositivo acima citado da LGT (Parágrafo Único do Artigo 18), decidiu liberar inteiramente, sem nenhuma restrição, a entrada de capital estrangeiro através do Decreto n. 2.591 de 15 de maio de 1998 que reza: “As concessões, permissões e autorizações para exploração de serviços de telecomunicações poderão ser outorgadas a empresas constituídas sob as leis brasileiras, com sede e administração no país, cujos sócios ou acionistas sejam pessoas naturais residentes no Brasil ou empresas constituídas sob as leis brasileiras e com sede e administração no país”.

Vale registrar ainda outro desdobramento do Acordo Geral de Telecomunicações da OMC na seqüência das ações do Governo FHC relacionadas à privatização do setor regulamentada pela LGT.

Na discussão sobre o tratamento que seria dado à indústria brasileira de telecomunicações nos contratos de concessão com as subsidiárias da Telebras, que precedeu ao leilão de privatização, falou-se, inicialmente, que as futuras concessionárias deveriam utilizar 35\% de peças e componentes fabricados no Brasil. Depois, falou-se em 20\% (Biondi, A.; 10/9/98). Poucos dias antes do leilão de privatização, o Ministro das Comunicações declarou "não podemos pôr um texto (nos contratos) que depois é questionado na OMC e somos obrigados a voltar atrás. Tudo o que fizermos em relação a isso será submetido pelos outros países à OMC. É uma questão de política de Governo responsável” (Freitas, R. de; 26/5/ 1998). O resultado, como se sabe, é que os futuros concessionários ficaram com liberdade total para importar equipamentos, vale dizer, não houve qualquer proteção ao fabricante nacional. 
Os fatos acima descritos, todos relacionados a LGT, tipificariam as características da nova política que buscamos identificar?

Creio que a própria inclusão das comunicações como serviço no âmbito da recém criada OMC já é um forte indicador desse novo contexto em que se "deslocam os termos e o terreno através do qual as decisões sobre as telecomunicações [são] tomadas”. O componente internacional que a formulação das políticas nacionais passa a ter revela-se até mesmo no texto da Exposição de Motivos ao Congresso Nacional da LGT, como já mencionado. Ademais, as pressões americanas públicas em Davos e as ações concretas do governo brasileiro na mesma direção confirmam a crescente integração das políticas externa e interna. Por outro lado, como é sabido que os Governos de países como França, Japão e Estados Unidos ainda estabelecem limites legais para a participação do capital estrangeiro em suas comunicações, parece que o Governo brasileiro, ao liberar inteiramente o ingresso desse capital, supõe uma coincidência dos seus interesses e os das empresas transnacionais (global players). Aqui, vale lembrar, como já vimos, que a indústria brasileira - em decorrência dos acordos celebrados na própria OMC - não mereceu qualquer proteção.

\section{Questões finais}

Antes de levantar algumas questões finais e com o objetivo de delimitar inequivocamente o campo de interesse desse artigo, faço três registros finais: primeiro, lembro que o Programa Nacional de Desestatização e as privatizações estaduais em andamento no Brasil não padecem de legalidade. Da mesma forma, a Emenda Constitucional e as leis que definiram o "processo especial” de reforma e privatização no setor de comunicações. ${ }^{11}$ Ademais, o Governo de FHC, eleito em 1994 e reeleito em 1998 em eleições livres, inclui as privatizações no seu programa de governo. A legalidade do processo não é, portanto, a questão que nos interessa aqui.

Segundo, não há dúvida de que o sucesso empresarial da Telebras e a sua boa imagem junto à opinião pública não eximem essa empresa do Estado da responsabilidade pelo tamanho da demanda reprimida durante o período de monopólio estatal na telefonia brasileira, tanto em relação à disponibilidade de aparelhos quanto à qualidade do serviço prestado (as razões que levaram à situação atual constituem uma outra questão). A necessidade de mais e melhores serviços telefônicos não é, certamente, a questão que nos interessa aqui.

Terceiro, é inegável o sucesso do Governo de FHC nas privatizações. Praticamente todas as principais empresas do Estado já foram vendidas. Somente a Telebras rendeu cerca de 20 bilhões de dólares. E, hoje, atuam no setor de comunicações no Brasil - ao lado dos grandes grupos nacionais - os principais global players com procedência dos Estados Unidos, da União Européia e da 
Ásia, como, por exemplo, a MCI (WorldCom), a Telefónica de España e a NEC. A eficiência do Governo na consecução de seus objetivos também não é, certamente, a questão que nos interessa aqui.

O que pretendemos foi exemplificar, através do estudo de caso da política de comunicações, os procedimentos da nova política do Governo de FHC. É ela que promove a "inserção do Brasil no mundo globalizado" e é através dela que se realizam e se justificam as privatizações.

O discurso justificativo, como se sabe, está centrado em dois pontos principais. Primeiro, naquilo que, com muita propriedade, já foi chamado de teoria da inevitabilidade e que significa "a policy position that tells us there is only one course - that there are no alternatives. This policy rules out all debate about the legitimacy of what is claimed to be inevitable. It precludes raising questions about justice, or power, or necessity. A policy of inevitability automatically resolves all issues beforehand, and in so doing, it rules out opposition” (Guback, T.; 1994).

Segundo, o discurso justificativo anuncia a criação de um mercado competitivo como garantia da melhoria da qualidade dos serviços (cf. MiniCom, 1995). Na verdade, o Governo de FHC, ao equacionar interesse público com mercado competitivo, enquadra a privatização das empresas do Estado no contexto da universalização de princípios promovida pelo neoliberalismo. Nesse contexto, vale registrar que a redefinição de interesse público, expressa na nova política de comunicações, é a mesma introduzida pela FCC americana, no bojo da aprovação do Telecommunications Act de 1996 (cf. Aufderheide, P.; 1996). O interesse público passa a se confundir com o interesse privado dos global players e das empresas não estatais que, segundo o Governo de FHC, garantirão a competitividade no mercado. Vale dizer: os papéis do Estado e do Governo convergem - a exemplo do que já ocorre em países como os Estados Unidos - porque ambos estão voltados para o interesse público agora redefinido em termos de competição e de mercado como reza o princípio neoliberal.

Creio que, a partir da identificação desta nova política e do argumento desenvolvido ao longo deste artigo, questões referentes a pelo menos quatro dimensões podem ainda ser colocadas. Refiro-me às dimensões estratégica, econômica, sócio-cultural e política. Exemplifico a seguir algumas das questões possíveis.

Do ponto de vista estratégico, cabe reconhecer que, desde os estudos acadêmicos liderados por Susan Strange (1992) até os diferentes cenários projetados pela Secretaria de Assuntos Estratégicos do Governo brasileiro para o próximo século (Salomon, M.; 2/11/1997), existe o reconhecimento das empresas transnacionais como principais global players do futuro.

No que se refere especificamente à privatização da Telebras, o ex-Ministro das Comunicações Sérgio Motta, falecido, havia advertido que "a Embratel vai ter que ser uma privatização cautelosa, porque envolve a banda X, que é de segurança 
nacional.(...)Você precisa garantir um controle societário tal, que seja independente em relação aos utilizadores da infra-estrutura da Embratel” (Leopoldo, R.; 30/5/ 1998). Diante da controvérsia surgida, uma Nota Oficial do Estado-Maior das Forças Armadas divulgada em 19 de junho de 1998 garantiu que "no processo de privatização da Telebras estão incluídos todos os instrumentos que asseguram de forma ampla e eficaz todos os interesses e necessidades ligadas à área de Segurança Nacional, o que inclui, naturalmente, os sistemas operados pelas Forças Armadas e da estrutura básica do governo" (Monteiro, T.; 20/6/98).

A questão que caberia colocar é se e de que maneira, diante da presença dos global players, o setor de comunicações como um todo, deveria ou não figurar entre aqueles considerados estratégicos ou relacionados à soberania do país e quais as conseqüências objetivas de uma decisão neste assunto para a formulação e implementação das políticas do setor.

Do ponto de vista econômico, a questão fundamental é saber se as promessas do Governo em relação à competição e à melhoria dos serviços serão cumpridas. Como se sabe, a abertura total do mercado de telefonia promovida pelo Governo brasileiro provocou estranheza até mesmo entre empresários, como no ex-presidente da Comissão de Valores Imobiliários (cf. Ferrari, L., 18/5/1998).

Até aqui, a privatização apenas introduziu a competição restrita de global players - isoladamente ou associados a parceiros nacionais - em áreas novas (telefonia celular, DTH) ou anteriormente monopolizadas pelo Estado (telefonia fixa). Fala-se até mesmo na existência de um novo Tratado de Tordesilhas de vez que a Aliança Pan-americana, anunciada em março de 1998 entre a MCI a Telefónica de España e a Portugal Telecom, adquiriu o controle das unidades mais importantes da Telebras, vale dizer, a Telesp fixa, a Tele Sudeste Celular, a Tele Leste Celular, a EMBRATEL e a Telesp Celular (cf. Tabela 1, acima e LAFIS, 19/ 8/1998) $)^{12}$.

Estaríamos saindo do monopólio estatal das telecomunicações - agora sem o seu patrimônio público eqüivalente - e caminhando na direção do oligopólio privado que já existe na radiodifusão, na TV a Cabo e nos mídia impressos? Não é exatamente isso que está acontecendo também nos Estados Unidos depois do Telecommunications Act de 1996 (Simons, 3/8/1998)? Até que ponto existem condições, em situações desse tipo, para que os interesses legítimos dos usuários/ consumidores prevaleçam? A experiência de outros países indica que, enquanto os usuários pessoas físicas pouco ou nada ganham com a privatização, os usuários empresariais são geralmente beneficiados pela reestruturação das tarifas e pela aceleração da expansão dos serviços mais modernos e sofisticados.

Várias questões do ponto de vista sócio-cultural foram tratadas em Lima (1998 e 1998a). Cabe apenas relembrar aqui o descompasso entre as ações do Governo e a maioria da opinião pública brasileira no que se refere às privatizações, em especial, ao Sistema Telebras. Estaria essa opinião pública fundada em valores 
arraigados em nossa cultura política como, por exemplo, as diferentes concepções do papel do Estado e do Governo? Quais as conseqüências de uma política que deliberadamente contraria esses valores?

Finalmente, do ponto de vista político, sabendo-se que o controle das comunicações é uma questão que ultrapassa, em muito, a dimensão econômica, cabe indagar quais as implicações que a propriedade e o controle oligopolísticos do setor, na sua dupla lógica econômica e simbólica, acarretam para a consolidação democrática no Brasil? ${ }^{13}$

Outubro 1998

\section{Anexo \\ PRIVATIZAÇÃO DAS COMUNICAÇÕES CALENDÁRIO GERAL: 1995/98}

\begin{tabular}{|l|l|}
\hline \multicolumn{1}{|c|}{ Datas } & \multicolumn{1}{c|}{ Fatos Relevantes } \\
\hline $\mathbf{1 9 9 5}$ & \multicolumn{1}{|c|}{} \\
\hline Janeiro & $\begin{array}{l}\text { Posse do Governo de FHC } \\
\text { Instalação da OMC } \\
\text { Lei do Cabo } \\
\text { cont. negociações Acordo Telecomunicações (OMC) }\end{array}$ \\
\hline Fevereiro & $\begin{array}{l}\text { Proposta EC de quebra monopólio estatal telecomunicações } \\
\text { enviada ao Congresso Nacional }\end{array}$ \\
\hline Agosto & EC n. 8 \\
\hline $\mathbf{1 9 9 6}$ & $\begin{array}{l}\text { Termo de Cooperação BRA/UIT } \\
\text { Contratação McKinsey }\end{array}$ \\
\hline Junho & Lei Mínima (privatização DTH, celular B) \\
\hline Julho & PL da LGT enviado ao CN \\
\hline Dezembro & Fórum de Davos \\
\hline $\mathbf{1 9 9 7}$ & Acordo Geral de Telecomunicações (OMC) \\
\hline Jan/Fev & LGT \\
\hline Fevereiro & Decreto 2591/98 \\
\hline Julho & $\begin{array}{l}\text { Ratificação do BR ao AGT na OMC } \\
\text { Prazo final inclusão compromissos na Lista/AGT }\end{array}$ \\
\hline $\mathbf{1 9 9 8}$ & Privatização do sistema Telebras \\
\hline Maio & \\
\hline Junho & \\
\hline Julho & \\
\hline
\end{tabular}




\section{Notas}

1 Uma primeira versão deste texto com o título “Peripheral Realism: Communications Policy in Brazil” foi apresentada na 26th Annual Telecommunications Policy Research Conference, (TPRC); 3-5/10/1998; Alexandria, VA, EUA.

2 Registro a semelhança desse novo paradigma de política com as políticas públicas implantadas na Argentina a partir do Governo Meném e que encontram sua fundamentação teórica no "realismo periférico" do ex-funcionário do Ministério das Relações Exteriores da Argentina, Carlos Escudé, (cf. Escudé, C.; 1992 e 1995).

3 Exemplo disso é o escopo limitado das restrições definidas no Modelo de Reestruturação e Desestatização do Sistema Telebras (Artigo $7^{\circ}$ ) conforme o Decreto 2.546 de 14/4/1998.

4 Isto não significa, como já observei em outro local, que a estrutura histórica do sistema brasileiro de comunicações, tenha se alterado. Prevalece, ainda, a concentração da propriedade, a vinculação com elites políticas e grupos familiares, além da hegemonia de um único grupo nacional, agora associado a global players (Lima, 1998b).

$5 \quad$ Nos Estados Unidos, estima-se que o setor representará $1 / 6$ ou cerca de $17 \%$ de toda a economia americana no ano 2.000. "Em termos globais, é possivel afirmar que este é o setor da economia que mais cresce e mais crescerá até depois do início do próximo milênio. Isso será medido na base de dezenas de trilhões de dólares nos próximos dez anos”, afirmou o presidente da Federal Communication Commission americana, em 1995 (Hundt, R., 8/11/95).

6 O pedido de crédito suplementar para fazer face a essa e outras novas despesas acordadas em um Aditivo ao Termo de Cooperação original tem uma melancólica história de aprovação no Congresso Nacional. Durante várias semanas, deputados do Bloco de Oposição solicitaram explicações sobre o assunto ao Relator da matéria que não as tinha. Uma Nota Técnica do MiniCom foi finalmente encaminhada à Comissão em 8/12/97 referindo-se a despesas que já haviam sido comprometidas (o Aditivo foi assinado em abril de 1997) e a contratos realizados sem licitação sobre os quais o Congresso não teve qualquer participação. No dia da votação (10/ 12/1997), o Deputado Sérgio Miranda, PCdoB-MG, registrou o seguinte protesto: "São três as razões que nos levam a votar "não": consideramos que a forma de contratar consultorias no Exterior pode ser uma burla à Lei n. 8.666/93, que exige licitação. O segundo aspecto é que nós consideramos que transferir para uma agência internacional, mesmo sendo um órgão da ONU, a definição da forma de contratação dessas consultorias é uma abdicação de nossa soberania. $\mathrm{O}$ terceiro aspecto são os valores envolvidos. Achamos excessivos os valores envolvidos na contratação dessas consultorias” (cf. Atas da Comissão Mista de Planos, Orçamentos Públicos e Fiscalização da Câmara dos Deputados, esp. dias 03 (número 1089/97) e 10/12/1997 (número 1123/97).

7 As informações aqui apresentadas constam da Nota Técnica do MiniCom enviada ao Congresso Nacional em 8/12/1997.

8 Em sua primeira declaração como novo vice-secretário geral da UIT, o brasileiro Roberto Blois afirmou; "Acredito que a UIT tem que operar de forma a responder com agilidade às reivindicações das empresas privadas, para que elas não precisem buscar apoio em outro tipo de organização”. (cf. Corrêa, M. 23-25/10/1998).

9 Em trabalho futuro, pretendo estudar a posição brasileira ao longo da Rodada Uruguai. No princípio, Brasil e Índia lideraram o grupo de países que resistiam às exigências dos Estados Unidos. A posição brasileira, todavia, alterou-se radicalmente no curso das negociações. (Cf. Hamelink, 1994).

10 Até outubro de 1998, o Congresso Nacional não havia referendado o Quarto Protocolo do AGCS da OMC. A Mensagem do Poder Executivo sobre a matéria só foi remetida ao Congresso Nacional em 23 de dezembro de 1997 (Mensagem n. 1.637/1997) e o Relatório favorável do 
Deputado Benito Gama, PFL-Bahia, na Comissão de Relações Exteriores da Câmara dos Deputados, aguarda sua entrada na pauta de votação.

11 É bem verdade que analistas do TCU questionaram a propriedade dos procedimentos técnicooperacionais específicos definidos pela LGT porque "divergentes das desestatizações tradicionalmente conduzidas no âmbito do PND”, sobretudo no que se refere aos artigos $196 \mathrm{e}$ 197. (cf. Mazzoli, M.B. L.C., Nota Técnica, TCU). Além disso, o Bloco de Oposição no Congresso Nacional interpelou judicialmente a Constitucionalidade de vários artigos da LGT através de ADIN de 9/9/1997. Destaque-se o Artigo 210 que exclui as licitações para concessões, permissões e autorizações de serviço de telecomunicações e de uso de radiofreqüência das normas e procedimentos definidos na Lei n. 8.666/93.

12 Não posso discutir aqui as conseqüências das privatizações para a indústria de equipamentos do setor. Há uma intensa reacomodação no mercado, considerando que a Ericsson é fornecedora da Telefónica de España, da Itália Telecom e da Telia.

13 Tratei dessas questões em Lima, 1997.

\section{Bibliografia}

ADIN (Ação Direta de Inconstitucionalidade) proposta pelo PC do B, PT, PDT e PSB, em 9/9/1997 (Protocolo n. 038484).

ALLEN, D. “The WTO Telecommunications Agreements: Policy between Trade and Networks". Trabalho apresentado a XIIa. Conferência da International Telecommunications Society-ITS; Estocolmo, Suécia, Junho, 1998.

ATAS. Comissão Mista de Planos,Orçamentos Públicos e Fiscalização; Departamento de Taquigrafia, Câmara dos Deputados, Novembro e Dezembro de 1997.

AUFDERHEID, P. “Competição, concentração e o interesse público: o Telecommunications Act dos EUA de 1996”. In Comunicação\&política, n.s., v.3, n.2, 1996, p. 154-172.

BARBOSA, R. "Privatização à brasileira”. Correio Braziliense, 29/7/1997, p. 1-21.

BERLINCK, D. “Telecomunicações enchem os olhos de estrangeiros”. O Globo, Economia, 16/02/ 1997, p. 40.

BIONDI, A. "Yes, nós somos miseráveis bananas". In Folha de São Paulo <fsp/dinheiro/ fi10099814.htm>, 10/9/1998.

COMOR. E. A. "The re-tooling of American hegemony: U.S. foreign communication policy from free flow to free trade”. In A. Sreberny-Mohammadi et alii (eds.). Media in Global Context-A Reader; London: Arnold, 1997, p. 194-206.

CORRÊA, M. “Brasileiro integra entidade de teles”. Gazeta Mercantil, 23-25/10/1998, p. A-14.

COWIE, C. e Marsden, C.T. "Convergence, Competition and Regulation: Programming and Navigating through Digital Pay-TV Bottlenecks”. Trabalho apresentado na XXVIa Telecommunications Policy Research Conference-TPRC, Alexandria, VA, Outubro, 1998.

DATAFOLHA. “O Governo deveria privatizar o Sistema Telebras ?” In Folha de São Paulo, EspecialTelebras, 25/7/1998, p. 10.

ESCUDÉ, C. Realismo Periférico: Fundamentos para la Nueva política Exterior de Argentina. Buenos Aires: Planeta, 1992.

ESCUDÉ, C. El realismo de los Estados Débiles. Buenos Aires: Grupo Editor Latinoamericano, 1995.

FERNANDES, B. “Poder e Palavras: Silêncio dos Inocentes”. In Carta Capital, Ano III, n. 80, 19/8/ 1998, p. 28-35.

FERRARI, L. “Abertura à participação externa divide mercado”. Gazeta Mercantil, B-4, 18/5/1998.

FOLHA DE SÃO PAULO. Cobertura do Forum de Davos; 20/01; 2,3 e 4/02/1997. 
FREITAS, R. de. “L.C. Barros: Concessão deve ficar nos parâmetros da OMC”. Agência Estado, 26/ 6/1998.

GAMA, B. Relatório-Mensagem n. 1.637 de 1997. Comissão de Relações Exteriores e de Defesa Nacional, Câmara dos Deputados (s/d).

GALHARDO, R. “Contrários a leilão são retrógrados, diz FHC”. Folha de São Paulo, 27/7/1998, p. $1-8$.

GUBACK, T. Counterclockwise: Dallas Smythe’s Contribution to Communication Policy and Research. Occasional Paper Number 1. Institute of Communications Research; U. of Illinois at Urbana-Champaign, 1994.

HAMELINK, C. J. The Politics of World Communication. London: Sage, 1994.

HAWKINS, R. "Infra-Estrutura de Informação e Comunicações: Ambições Globais e Realidades Regionais”. In COUTINHO, L. et alii (eds.). Telecomunicações, Globalização e Competitividade. São Paulo: Papirus, 1995.

HILLS, J. “A teoria da dependência e sua atual relevância: instituições internacionais de telecomunicações e poder estrutural”. In BOLAÑO, C. (coord.). Privatização das Telecomunicações na Europa e na América Latina. Aracaju: EDUFS, 1997, p. 13-32.

HUNDT, R. “O Revolucionário americano” (entrevista a Osmar Freitas Jr.), Isto É, Edição 1362, 8/ 11/1995, p. 4-7.

HUNTINGTON, S. “A Erosão dos Interesses Nacionais dos EUA”. Foreign Affairs-Edição Brasileira; n.12, 9/1997, p. 12-19.

IBOPE. <www.ibope.com.br/pp_wef00.htm> Opinião, Pesquisas Atuais, Privatização, 3/1998.

LAFIS-Pesquisa e Investimento em Ações na América Latina. "Pós-Privatização: Conexão das Teles”. Carta Capital, Ano III, n. 80, 19/8/1998, p. 60-64.

LEOPOLDO, R. “Nas Mãos dos Gigantes”. Correio Braziliense, 30/5/1998, p.1-24.

LIMA, V.A. de. "Política de Comunicações no Brasil: Velhos e Novos Atores”. Paper apresentado no XXI International Congress of the Latin American Studies Association, Chicago, Illinois, Setembro, 1998b.

LIMA, V. A. de. “Os Mídia e a Política”. In RUA, M. das G. e Carvalho, I. (orgs.). O Estudo da Política: Tópicos Selecionados. Brasília: Paralelo 15, 1998a, p. 209-230.

LIMA, V.A. de. “Os mídia e a Representação da Política”. In ALMEIDA, J. e Cancelli, V. (orgs.). Estratégia-A Luta Política Além do Horizonte Visível. São Paulo: PT/Fundação Perseu Abramo, 1998, p. 105-112.

LIMA, V.A. de. “Comunicações, Política e Democracia”. In CASTRO, M.F. de. e Trindade, A.A.C. (orgs.). Sociedade Democrática no Final do Século. Brasília: Paralelo 15, 1997, p. 127-153.

LOBATO, E. “Telecomunicação terá R\$ 83,5 bi até 2003”. Folha de São Paulo, Internet <fsp/ dinheiro/fi210312.htm>, 21/03/1997.

LOPES, N. “Ganhar ou Perder”. Correio Braziliense, 21/02/1997, p. 1-19.

MAHONEY, E. “Comércio e política internacional de telecomunicações” in Bolaño, C., op. cit., 1997, p. 33-58.

MAZZOLI, M.B.L.C. Nota Técnica- Assunto: Desestatização do Sistema Telebras. Tribunal de Contas da União. 9a. SECEX-3a. Divisão, 16/4/1998.

MCKINSEY \& COMPANY, INC. <www.mckinsey.com>.

MINISTÉRIO DAS COMUNICAÇÕES. Nota Técnica-Termo de Cooperação com a UIT. Gabinete do Ministro-Assessoria Especial, 8/12/1997.

MINISTÉRIO DAS COMUNICAÇÕES/McKINSEY \& COMPANY, INC. Transformando o Setor de Telecomunicações do Brasil Rumo ao Século 21. Brasília, 11/1996 (60pp.).

MINISTÉRIO DAS COMUNICAÇÕES. Reforma Estrutural do Setor de TelecomunicaçõesPremissas e Considerações Gerais. Brasília, 1995.

MOBERG, D. "Power Grab-Big business wants to tighten its hold with a new global trade pact”. In The Progressive, vol. 62, n.3, March, 1998, pp.24-26. 
MONTEIRO, T. “Forças Armadas defendem venda da Telebras”. In O Estado de São Paulo, 20/6/ 1998, p. A-5.

OHMAE, K. O Fim do Estado Nação. Rio de Janeiro: Campus, 1996.

ORGANIZAÇÃO MUNDIAL DO COMERCIO. Quarto Protocolo do Acordo Geral sobre o Comércio de Serviços (AGCS), Brasil-Lista de Compromissos Específicos. Genebra, 1997.

PINHEIRO, A. J. "Dia de festa no gabinete do ministro"; Correio Braziliense, 30/7/1998, p. 1-21.

REUTER, A. C. e Elstrodt, H.-P. Entrevista: “Nunca houve tanto dinheiro no Mundo”. Época, Ano I, n. 13, 17/8/1998, p. 100.

RODRIGUES, F. “Brasil lidera as privatizações no planeta”. Folha de São Paulo; Especial-Privatização, 7/4/1998, p. 2.

SALOMON, M. “Governo aponta os riscos da globalização”. Folha de São Paulo, 2/11/1997, p. 1-17.

SIMONS, J. "Na Telefonia, o monopólio contra-ataca”. The Wall Street Journal Americas in $O$ Estado de São Paulo, 03/08/1998, p. B-11.

STRANGE, S. “States, Firms and Diplomacy”. International Affairs, vol. 68, n.1, January, 1992, pp.1-15.

THORSTENSEN, V. “O papel da Organização Mundial do Comércio na nova ordem econômica internacional”. vv.aa. Competitividade Internacional e Desenvolvimento das Regiões. São Paulo: Konrad-Adenauer Stitung, Coleção Debates n. 15, 1998, p. 33-70.

UIT-União Internacional de Telecomunicações <www.itu.ch>.

UIT-Termo de Cooperação; Documento do Projeto; Aditivo n. 1 (UIT No.9-BRA/95/05).

VEJA. Ed. 1501, Ano 30, n. 30, 25/06/97, p.110.

VEJA. Ed. 1476, Ano 29, n.52, 25/12/96, pp.176-179.

VOX POPULI. "Voto é moeda de troca”; Correio Braziliense, 6/8/1998, p. 1-8.

VOX POPULI. "Privatização mal vista”; Correio Braziliense, 17/8/1998, p. 1-9.

Legislação citada

Constituição de 1998.

Decreto n. 2.591 de 15/5/1998.

Decreto n. 2.546 de 14/4/1998.

Emenda Constitucional $\mathrm{n}^{\circ}$ 8/1996.

Lei do Cabo (Lei 8.977/1995).

Lei Geral de Telecomunicações (Lei 9.472/1997).

Lei Mínima (Lei 9.295/1996).

Mensagem do Poder Executivo N.1637/1997.

Programa Nacional de Desestatização-PND (Leis 8.031/90 e 9.491/97).

Projeto de Lei (LGT) no 2.648/1996 (inclui Exposição de Motivos $n^{\circ}$ 231/MC).

Telecommunications Act (Lei Pública n. 104-104, 110 Estatuto 56 dos EUA).

Revistas

Época.

Veja.

Isto É.

Carta Capital.

Jornais

Correio Braziliense (DF).

Folha de São Paulo (SP). 
Gazeta Mercantil (SP).

O Estado de São Paulo (SP).

O Globo (RJ).

The Wall Street Journal (Washington, D.C.).

\section{Resumo}

O trabalho é um estudo de caso do descompasso existente entre o princípio neoliberal da abertura plena dos mercados e a cultura política dominante no Brasil, tendo como exemplo a nova política de privatização das comunicações.

\section{Abstract}

The article brings a case study arouse in the lag between the neoliberal principle of full market openness and the dominant political culture in Brazil, having as an example the new communications privatization policy.

Palavras-chave: Brasil. Estado. Governo. Interesse Público. Interesse Privado. Privatização da Telebras.

Key-words: Brazil. State. Government. Public interest. Private interest. Telebras privatization. 